\title{
Hemodynamic Adaptation to Reduced Renal Mass in Early Postnatal Development
}

\author{
ROBERT L. CHEVALIER ${ }^{(19)}$ \\ Department of Pediatrics, University of Virginia School of Medicine, Charlottesville, Virginia, USA
}

\begin{abstract}
Summary
Radioactive microspheres, clearance methodology, and glomerular counting techniques were used to compare hemodynamic changes resulting from uninephrectomy at birth with those of sham-operated guinea pigs 8-13 days of age and 18-24 days old. Left renal blood flow doubled from 10-20 days of age, and was approximately $65 \%$ higher in animals with reduced renal mass. Cardiac output also doubled from 10-20 days of age but was not significantly affected by uninephrectomy whereas mean arterial blood pressure rose with normal or compensatory renal growth. There was a progressive fall in renal vascular resistance that paralleled the drop in total peripheral resistance during normal growth, but the fraction of cardiac output supplying the remaining kidney of renoprival guinea pigs rose significantly from $7 \%$ at 10 days to $11 \%$ at 20 days of age. Whole kidney filtration fraction averaged 0.25-0.29 for all groups. There was no change in cortical blood flow distribution with age or after uninephrectomy: 50, 30, and $20 \%$ supplied outer, middle, and inner thirds, respectively. Glomerular perfusion rate increased proportionately in all cortical levels during normal or compensatory renal growth, and was higher in outer and inner cortical thirds than in the middle cortex. It is concluded that systemic and intrarenal hemodynamic responses to uninephrectomy at birth are similar to the pattern of normal maturation. Reduction in renal mass and normal somatic growth provide additive stimuli resulting in maintenance of homeostasis.
\end{abstract}

\section{Abbreviations}

$\overline{\mathbf{A P}}$, mean arterial blood pressure

BW, body weight

$E_{\text {in }}, E_{P A Y}$, renal extraction of inulin, PAH

GFR, glomerular filtration rate

IC, inner cortex

$\mathrm{KW}$, kidney weight

$M C$, middle cortex

OC, outer cortex

PAH, $p$-amino-hippuric acid

Renal blood flow increases with normal development (9) and as a result of compensatory renal hypertrophy at any age (12). In the guinea pig uninephrectomized at birth, there is an accelerated increase in superficial single nephron glomerular filtration rate by 10 days of age (5). By 22 days of age, uninephrectomized animals have achieved $90 \%$ of the glomerular filtration rate for two kidneys of sham-operated littermates (5). These changes are associated with accelerated recruitment of glomeruli which are underperfused at birth but are completely perfused in the adult (6).

The present study was designed to investigate hemodynamic factors that underlie the compensatory adaptation of the guinea pig uninephrectomized at birth. Clearance and microsphere techniques were used to measure cardiac output, renal blood flow, and intracortical distribution of blood flow. Glomerular perfusion rate was calculated from regional blood flow and the number of glomeruli containing India ink injected in vivo.
MATERIALS AND METHODS

Experiments were conducted on 66 guinea pigs ranging in weight from 130-290 g. Within the first $36 \mathrm{~h}$ of life, animals were weighed, anesthetized with halothane, and the right kidney was exposed through a flank incision and removed (Group N) or left untouched (Group S). The incision was closed and coated with collodion and the animal was returned to its mother until weaning at 14 days of age. For both sham-operated and uninephrectomized animals, experiments were performed at 8-13 days of age (Groups IS and IN), and 18-24 days of age (Groups IIS and IIN). The day before the experiment, animals in Group I were separated from their mothers.

Clearance studies. After overnight fast with water ad libitum, the animal was anesthetized with intraperitoneal Inactin, $10 \mathrm{mg} / 100$ $\mathrm{g}$ body weight, and placed on a thermostatically controlled heating table to maintain rectal temperature at $39 \pm 0.5^{\circ} \mathrm{C}$. Tracheostomy was performed, and the right jugular vein was cannulated with polyethylene tubing for infusion of $0.9 \%$ saline containing $\left[{ }^{14} \mathrm{C}\right]$ inulin $2 \mu \mathrm{Ci} / \mathrm{ml}$, or $\left[{ }^{14} \mathrm{C}\right] \mathrm{PAH}$ (New England Nuclear, Boston, $\mathrm{MA}), 8 \mu \mathrm{Ci} / \mathrm{ml}$, at a rate of $0.3 \mathrm{ml} / 100 \mathrm{~g} \mathrm{BW} \cdot \mathrm{h}$. The left jugular vein was cannulated for infusion of fresh heparinized donor plasma, and a volume equal to $1 \% \mathrm{BW}$ was infused during the first $45 \mathrm{~min}$ followed by maintenance infusion at $1.2 \mathrm{ml} / \mathrm{h}$ (Group I) or $0.6 \mathrm{ml} / \mathrm{h}$ (Group II). These rates of plasma replacement were previously shown to maintain constant hematocrit during the experiment (5). $\mathrm{AP}$ was measured from a cannula in the right carotid artery connected to a Statham 23 ID pressure transducer and a Hewlett Packard 7754B recorder. The left kidney was exposed through an abdominal incision, placed in a lucite cup and bathed in $0.9 \%$ saline warmed to $39 \pm 0.5^{\circ} \mathrm{C}$. The left ureter was cannulated for collection of urine in a small weighed cup. After a 45-min equilibration period. two 20-30-min urine collections were obtained. In some animals, intratubular pressure was measured by micropuncture techniques during urine collections and results are reported separately (7). Arterial blood samples $(100 \mu \mathrm{l})$ were obtained at the beginning and end of each urine collection period, and were replaced by an equal volume of donor s. hole blood. Hematocrit was measured in heparinized capillary tubes.

Immediately after the urine collection periods, hydrostatic pressure in the left renal vein (RVP) was measured using a $2-4-\mu \mathrm{m}$ micropipette and servonulling device. The distal renal vein was then punctured with a $27 \mathrm{G}$ needle and $100 \mu \mathrm{l}$ heparinized blood was withdrawn at a rate of $100 \mu \mathrm{l} / \mathrm{min}$. An additional $100 \mu \mathrm{l}$ sample of arterial blood was simultaneously obtained to determine renal extraction of inulin $\left(\mathrm{E}_{\text {in }}\right)$ or PAH $\left(\mathrm{E}_{\mathrm{PAH}}\right)$. After micropuncture and clearance studies, the left kidney was decapsulated, drained and $\mathrm{KW}$ was determined.

Samples of plasma and urine $(5 \mu \mathrm{l})$ were discharged into vials containing $0.5 \mathrm{ml}$ water and $5 \mathrm{ml}$ PCS Solubilizer (AmershamSearle Corp.). Activity of $\left[{ }^{14} \mathrm{C}\right]$ was counted in a liquid scintillation spectrometer (Beckman Instruments, Fullerton, CA).

GFR was determined by inulin clearance $\left(\mathrm{C}_{\mathrm{in}}\right)$, and renal plasma flow (RPF) was calculated as:

$$
\mathrm{RPF}=\mathrm{C}_{\mathrm{in}} / \mathrm{E}_{\mathrm{in}}=\mathrm{C}_{\mathrm{PAH}} / \mathrm{E}_{\mathrm{PAH}}
$$


Filtration fraction (FF) was given by $\mathrm{E}_{\mathrm{in}}$, and renal blood flow (RBF), was derived from:

$$
\mathrm{RBF}=\mathrm{RPF} /(1-\mathrm{Hct})
$$

where Hct, hematocrit.

Renal vascular resistance (RVR) was calculated as:

$$
\mathrm{RVR}=(\overline{\mathrm{AP}}-\mathrm{RVP}) / \mathrm{RBF}
$$

where RVP, left renal vein.

Microsphere studies. Animals were assigned to Groups I and II as in clearance experiments. After induction of anesthesia with sodium pentobarbital, $3 \mathrm{mg} / 100 \mathrm{~g} \mathrm{BW}$ intraperitoneally, the guinea pig was placed on a heating table. To maintain euvolemia, donor plasma was infused intravenously as in micropuncture experiments. A polyethylene catheter was threaded down the right carotid artery such that the catheter tip lay at the aortic root. The abdominal aorta was then exposed through a midline abdominal incision, and was cannulated at the aortic bifurcation. Each arterial catheter was connected to a Statham 23 ID pressure transducer for simultaneous recording of AP. Heparin, $10 \mathrm{IU} / 100 \mathrm{~g} \mathrm{BW}$, was then infused and the animal was allowed to equilibrate for $15 \mathrm{~min}$

Latex microspheres labeled with $\left[{ }^{85} \mathrm{Sr}\right], 14.5 \pm 1.0 \mu$ in diameter (3M, St. Paul, MN), were suspended in 10\% dextran and Polysorbate 80 by vigorous agitation (Vortex Genie, Scientific Ind. Bohemia, NY). While blood was withdrawn from the abdomina aorta at $0.7 \mathrm{ml} / \mathrm{min}$ using a precision withdrawal pump (Harvard Apparatus, Millis, MA), $50-80 \times 10^{3}$ microspheres were injected in the carotid catheter and flushed with normal saline. After 5 min, $1.0 \mathrm{ml}$ India ink (Higgins No. 4465, Newark, NJ) was slowly infused through the carotid catheter. The animal was then sacrificed with an infusion of saturated potassium chloride, and the kidney(s) were removed, decapsulated, weighed, and fixed in $10 \%$ formalin. Radioactivity of the blood sample and kidneys was measured in a gamma scintillation counter (Beckman Instruments, Irvine, CA), and the syringe containing microspheres was counted before and after injection.

The left kidney was then bisected and six cores (two each from upper, middle and lower pole, $3 \mathrm{~mm}$ in diameter) were punched out perpendicular to the surface of the kidney. Under a dissecting miscroscope, glomeruli could be identified by the presence of India ink, and medullary tissue was cut away. The remaining cortex was divided into $\mathrm{OC}, \mathrm{MC}$, and IC and the slices from each level were pooled for measurement of radioactivity. In each case, activity of the medullary pieces amounted to less than $3 \%$ of the cortical activity. The separate OC, MC, IC samples were then digested in $0.5 \mathrm{ml} 25 \%$ hydrochloric acid at $40^{\circ} \mathrm{C}$ for $14 \mathrm{~h}$. Digestion was stopped by the addition of $4.5 \mathrm{ml}$ cold distilled water and the suspension was mechanically stirred. Aliquots of 25 $\mu \mathrm{l}$ (OC), or $50 \mu \mathrm{l}$ (MC and IC) were taken at three equally spaced levels in triplicate (total of nine aliquots per suspension) and were discharged on microscope slides. The total number of glomeruli identified by the presence of India ink particles was counted under a dissecting microscope. The mean number of glomeruli per slide was multiplied by the appropriate dilution factor and divided by the weight of the tissue to obtain the glomerular concentration for each cortical level.

Assuming that microspheres were evenly mixed in the aortic blood, and that all microspheres were trapped in a single pass through the microcirculation, the following relationship may be derived:

$$
\mathrm{CO}=\frac{\mathrm{M} \cdot \mathrm{q}}{\mathrm{b}}
$$

where $\mathrm{CO}$, cardiac output (less coronary blood flow); $\mathrm{M}$, radioactivity of injected microspheres; $q$, blood withdrawal rate; and $b$, radioactivity of blood sample;

$$
\mathrm{RBF}=\frac{\mathrm{K} \cdot \mathrm{q}}{\mathrm{b}}
$$

where $\mathrm{K}$, radioactivity of whole kidney; and

$$
\mathrm{GPR}=\frac{\mathrm{k} \cdot \mathrm{q}}{\mathrm{b} \cdot \mathrm{NG}}
$$

where GPR, glomerular perfusion rate; $\mathrm{k}$, radioactivity of cortical slices; and NG, number of glomeruli in cortical slices.

Total peripheral resistance (TPR) was calculated as TPR = $(\overline{\mathrm{AP}}-\mathrm{RVP}) / \mathrm{CO}$.

To evaluate the possibility of preferential flow of microspheres to the OC due to axial streaming artifact, seven additional guinea pigs aged 13-22 days were infused with both $\left[{ }^{141} \mathrm{Ce}\right], 15.3 \pm 0.9$ and $\left[{ }^{85} \mathrm{Sr}\right], 9.2 \pm 0.7 \mu$ spheres. Approximately 50,000 microspheres of each size were injected, and radioactivity in $\mathrm{OC}, \mathrm{MC}$, and IC cortical slices were determined as above. The appropriate fraction of $\left[{ }^{85} \mathrm{Sr}\right]$ activity appearing in the $\left[{ }^{141} \mathrm{Ce}\right]$ channel was subtracted from the latter.

Statistical analysis. Data were evaluated by two-way analysis of variance using the Statistical Analysis System (S.A.S. Institute, Inc., Cary, NC). The effects of age and of uninephrectomy were examined separately, and the presence of interaction between these variables was also sought. For studies of regional cortical blood flow distribution, glomerular concentration, and glomeraular perfusion rate, the first level of analysis addressed overall differences between cortical levels. After accounting for the demonstrated differences between cortical levels, a second level of analysis permitted evaluation of the effects of age and uninephrectomy on each of these parameters. Differences between clearance and microsphere groups were sought for body weight, kidney weight, and renal blood flow using three-way analysis of variance. Linear regression analysis was performed using the method of least squares. Statistical significance was defined as $P<0.05$.

\section{RESULTS}

With respect to age, body weight, and kidney weight, animals in each of the four groups subjected to clearance experiments did not differ significantly from those studied with microspheres (Tables 1 and 2).

Clearance studies. As shown in Table 1, uninephrectomy resulted in no impairment of body growth, and $\mathrm{KW}$ increased with normal or compensatory growth. $\overline{\mathrm{AP}}$ rose significantly with normal growth or as a result of uninephrectomy, and the effect of uninephrectomy was not influenced by age of the animal. Renal plasma flow and renal blood flow increased with normal growth, and with compensatory adaptation in Groups IN and IIN. There was a progressive fall in renal vascular resistance with normal renal development and an additional decrease as a result of uninephrectomy. GFR increased with age and as a result of uninephrectomy: the compensatory increment at 20 days was greater than that at 10 days $(P<0.0001)$. The rise in GFR paralleled renal plasma flow such that the whole kidney filtration fraction was similar in all groups. Renal venous pressure was not different in any of the groups.

Microsphere studies. Renal blood flow determined by microsphere technique for each group (Table 2) did not differ significantly from that measured with clearance methodology. Cardiac output increased and total peripheral resistance decreased with age, but neither parameter was significantly affected by uninephrectomy. As shown in Table 2 and Figure 1, renal blood flow increased in parallel with cardiac output in all groups except IIN, where the proportion of cardiac output supplying the hypertrophied kidney had increased significantly.

Figure 2 shows the intracortical distribution of blood flow and glomeruli as determined by microsphere and glomerular counting techniques. From 10-20 days of age, there was no change in cortical blood flow distribution, and uninephrectomy had no additional effect. Approximately half of the blood flow supplied the outer third of the cortex in each group, with the smallest fraction perfusing the juxtamedullary glomeruli $(P=0.0001)$. For the seven animals infused with two sizes of microspheres, the fraction of glomerular blood flow to the OC was $54.3 \pm 1.5 \%$ for $9 \mu$ spheres compared to $58.3 \pm 1.7 \%$ for $15 \mu$ spheres $(P=\operatorname{not}$ 
Table 1. Left kidney clearance studies ${ }^{1}$

\begin{tabular}{|c|c|c|c|c|c|c|c|}
\hline & & & & & & I vs II & $\mathrm{S} v s \mathrm{~N}$ \\
\hline & & IS & IN & IIS & IIN & \multicolumn{2}{|c|}{$P$ value } \\
\hline Age & (days) & $10.2 \pm 0.7$ & $10.9 \pm 0.8$ & $20.6 \pm 0.5$ & $21.2 \pm 0.6$ & & \\
\hline $\mathrm{BW}$ & (g) & $163 \pm 5$ & $161 \pm 8$ & $209 \pm 8$ & $206 \pm 10$ & 0.0001 & NS \\
\hline$\underline{\mathrm{KW}}$ & (g) & $0.89 \pm 0.04$ & $1.13 \pm 0.06$ & $1.05 \pm 0.04$ & $1.55 \pm 0.05$ & 0.0001 & 0.0001 \\
\hline$\overline{\mathrm{AP}}$ & $(\mathrm{mmHg})$ & $53.7 \pm 1.4$ & $58.8 \pm 1.2$ & $57.3 \pm 1.7$ & $60.8 \pm 1.6$ & 0.030 & 0.026 \\
\hline RPF & $(\mathrm{ml} / \mathrm{min})$ & $1.21 \pm 0.20$ & $2.19 \pm 0.17$ & $2.87 \pm 0.32$ & $4.53 \pm 0.46$ & 0.0001 & 0.0001 \\
\hline \multirow[t]{2}{*}{$\mathrm{RBF}$} & $(\mathrm{ml} / \mathrm{min})$ & $2.10 \pm 0.31$ & $3.72 \pm 0.31$ & $4.79 \pm 0.57$ & $7.85 \pm 0.81$ & 0.0001 & 0.0001 \\
\hline & {$[\mathrm{ml} /(\min \cdot \mathrm{g} \mathrm{KW})]$} & $2.35 \pm 0.37$ & $3.37 \pm 0.31$ & $4.56 \pm 0.53$ & $5.06 \pm 0.45$ & 0.0001 & 0.042 \\
\hline RVR & {$[\mathrm{mmHg} /(\mathrm{ml} \cdot \mathrm{min})]$} & $29.0 \pm 5.5$ & $15.4 \pm 1.3$ & $12.7 \pm 1.5$ & $8.3 \pm 1.0$ & 0.0002 & 0.0049 \\
\hline$n$ & & 9 & 9 & 11 & 10 & & \\
\hline GFR & $(\mathrm{ml} / \mathrm{min})$ & $0.34 \pm 0.05$ & $0.52 \pm 0.06$ & $0.58 \pm 0.04$ & $1.10 \pm 0.09$ & 0.0001 & 0.0001 \\
\hline FF & $(\%)$ & $0.29 \pm 0.02$ & $0.25 \pm 0.02$ & $0.25 \pm 0.02$ & $0.27 \pm 0.03$ & NS & NS \\
\hline RVP & $(\mathrm{mmHg})$ & $3.8 \pm 0.4$ & $3.3 \pm 0.3$ & $3.8 \pm 0.6$ & $3.1 \pm 0.2$ & NS & NS \\
\hline$n$ & & 8 & 8 & 7 & 6 & & \\
\hline
\end{tabular}

${ }^{1}$ Values are mean \pm SE. BW, body weight; $\mathrm{KW}$, kidney weight; $\overline{\mathrm{AP}}$, mean arterial blood pressure; RPF, renal plasma flow; RBF, renal blood flow; $\mathrm{RVR}$, renal vascular resistance; GFR, glomerular filtration rate; FF, filtration fraction; RVP, renal venous pressure; $n=$ number of animals; and NS, not significant.

Table 2. Left kidney microsphere studies ${ }^{1}$

\begin{tabular}{|c|c|c|c|c|c|c|c|}
\hline & & & & & & I $v s$ II & $\mathrm{S} v s \mathrm{~N}$ \\
\hline & & IS & IN & IIS & IIN & \multicolumn{2}{|c|}{$P$ value } \\
\hline Age & (day) & $11.4 \pm 0.2$ & $11.0 \pm 0.4$ & $20.0 \pm 0.3$ & $19.4 \pm 0.4$ & & \\
\hline $\mathrm{BW}$ & (g) & $171 \pm 10$ & $174 \pm 12$ & $232 \pm 18$ & $208 \pm 15$ & 0.0001 & NS \\
\hline $\mathrm{KW}$ & (g) & $0.84 \pm 0.03$ & $1.24 \pm 0.04$ & $1.15 \pm 0.09$ & $1.62 \pm 0.19$ & 0.0001 & 0.0001 \\
\hline $\mathrm{RBF}$ & $(\mathrm{ml} / \mathrm{min})$ & $2.52 \pm 0.36$ & $3.65 \pm 0.59$ & $4.88 \pm 0.99$ & $8.35 \pm 1.48$ & 0.0002 & NS \\
\hline $\mathrm{CO}$ & $(\mathrm{ml} / \mathrm{min})$ & $36.1 \pm 3.3$ & $53.4 \pm 5.2$ & $83.6 \pm 14.2$ & $78.5 \pm 14.6$ & 0.0057 & NS \\
\hline$\frac{\mathrm{RBF}}{\mathrm{CO}}$ & $(\%)$ & $6.9 \pm 0.5$ & $6.9 \pm 1.1$ & $5.8 \pm 0.5$ & $10.7 \pm 0.4^{2}$ & 0.0007 & 0.0001 \\
\hline $\begin{array}{l}\text { TPR } \\
n\end{array}$ & {$[\mathrm{mmHg} /(\mathrm{ml} \cdot \min )]$} & $\begin{array}{c}1.56 \pm 0.13 \\
5\end{array}$ & $\begin{array}{c}1.02 \pm 0.06 \\
5\end{array}$ & $\begin{array}{c}0.77 \pm 0.21 \\
5\end{array}$ & $\begin{array}{c}0.88 \pm 0.21 \\
5\end{array}$ & 0.019 & NS \\
\hline
\end{tabular}

${ }^{1}$ Values are mean \pm S.E. CO, cardiac output; TPR, total peripheral resistance; and definitions of other abbreviations, see footnote 1 of Table 1.

${ }^{2} P<0.0001$ vs IS, IN and IIS.

significant). Glomerular concentration was likewise highest in the OC for all groups $(P=0.0001)$, and decreased as a result of normal $(P=0.021)$ or compensatory $(P=0.011)$ renal growth. Glomerular perfusion rate was lowest in $\mathrm{MC}$ for all groups $(P<$ 0.05 ), and there was a parallel increase in glomerular perfusion rate in all cortical levels during normal $(P=0.0001)$ or compensatory $(P=0.0003)$ renal growth.

\section{DISCUSSION}

In view of recent evidence suggesting that $15 \mu$ microspheres may overestimate $O C$ blood flow in adult rabbits and rats (4), the use of the microsphere technique to determine glomerular perfusion rate must be justified. Källskog, et al. (11) found no evidence of axial streaming of spheres in the rat prepared for micropuncture, and the procedure used in the present study was similar. In 30 40-day-old rats, the proportion of spheres localized in the OC was significantly greater for $15 \mu$ than $9 \mu$ spheres at normal arterial blood pressure (90-100 $\mathrm{mmHg}$ ), but no difference was found at perfusion pressures of 70 or $40 \mathrm{mmHg}$ (Chevalier, unpublished observations). In the guinea pig, the lack of a significant difference in cortical blood flow distribution with $15 \mu$ and $9 \mu$ spheres suggests that a spurious concentration of larger spheres in the OC does not take place because arterial blood pressure is lower in this species. Because deeper cortical afferent glomerular arterioles join interlobular arteries at a more acute angle than those of outer cortical glomeruli, Bankir et al. (4) have argued that microspheres will be preferentially carried to glomeruli in the OC. Despite the perfusion of additional glomeruli as a result of uninephrectomy in guinea pigs of similar age, the proportion of recruited glomeruli is the same in OC and IC (6). It is therefore unlikely that changes in glomerular perfusion rate as determined in the present study resulted from methodologic artifact.

Because animals studied by clearance methods did not differ from those studied by microsphere techniques, data may be pooled for each group. The effects of normal growth on hemodynamics will be addressed first, followed by consideration of changes resulting from uninephrectomy. Adaptation to normal somatic growth will then be compared to the response to compensatory renal growth.

Normal growth. In the present study, renal blood flow increased during normal growth even when factored for renal mass. Because increase in renal blood flow followed the rise in cardiac output during normal maturation from 10-20 days, cardiac output may be a significant determinant of renal blood flow in the developing guinea pig. The observed rise in arterial blood pressure from 1020 days of age may be due to the increase in cardiac output, but the change in cardiac output was proportionately greater as evidenced by a fall in total peripheral resistance. Whether there is a primary increase in cardiac output during maturation, or whether the decrease in total peripheral resistance leads to a compensatory rise in cardiac output cannot be determined from these data. Patency of the ductus arteriosus may be dismissed as a factor mediating cardiac output in the age range studied, as this structure becomes irreversibly closed in the guinea pig within $72 \mathrm{~h}$ after birth (8). In view of the marked reduction in renal vascular resistance from 10-20 days of age, the increase in renal blood flow is presumably due to intrarenal vasodilatation as well as increased cardiac output.

In piglets, the proportion of cardiac output supplying both 


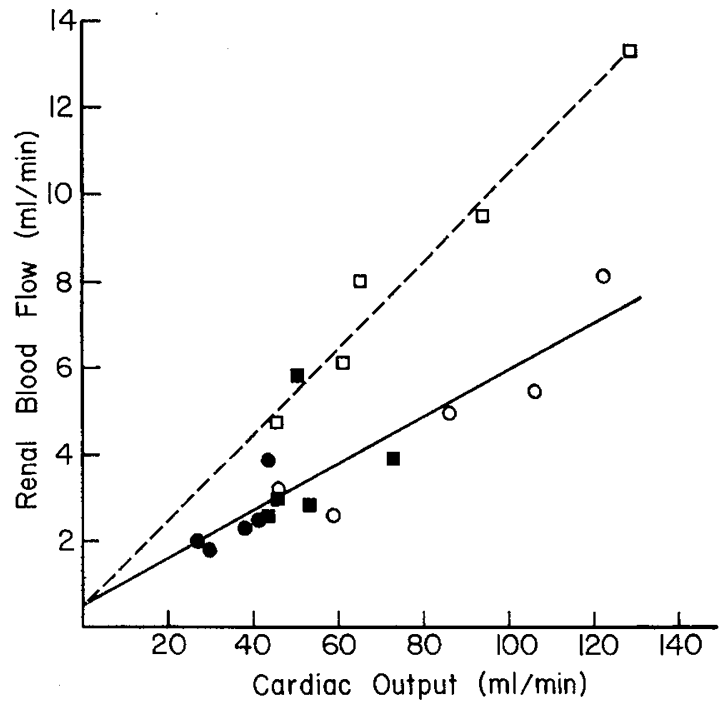

Fig. 1. Relationship between renal blood flow and cardiac output. For Groups IS, IN, and IIS, $\mathrm{y}=0.055+0.53$ (solid line, $r=0.86, P<0.0001$ ); for Group IIN, $\mathrm{y}=0.099+0.56$ (broken line, $r=0.98, P<0.0001$ ). The slopes of the lines are significantly different $(\mathrm{F}=7.47, P<0.02)$. Symbols are as follows: Group IS (@), Group IIS (O), Group IN (ם), Group IIN (口). Each point represents one animal.

kidneys increases from $5 \%$ during the first day of life to $12 \%$ by day 45 (9). In the rat, the fraction increases from $2 \%$ at $3 \mathrm{wk}$ of age to $16 \%$ at $8 \mathrm{wk}(2)$. It is likely that with maturation beyond 20 days of age, the fraction of cardiac output to the kidneys increases in the guinea pig as well.

Maintenance of a constant filtration fraction during normal maturation indicates that whole kidney glomerular filtration increased in parallel with renal blood flow. In the dog, filtration fraction does not change from birth to adulthood (13) whereas filtration fraction in the rat increases from 3\% at birth to $30 \%$ (adult level) by 18 days of age (10).

Determination of renal blood flow distribution by the microsphere technique has been applied in a number of developmental studies $(1,2,9,13,15,16)$. Glomerular perfusion rate was also determined in the puppy $(15)$, lamb $(1,16)$, and immature rat (2). In the present study, the relatively lower glomerular perfusion rate of the MC is similar to the glomerular perfusion pattern of the 6wk-old puppy (15), the 40-79-day-old lamb (1), and the 30-50day-old rat (2). The reasons for this distribution of glomerular perfusion rate in developing animals is not clear. OC glomerular perfusion rate was lower than that of juxtamedullary nephrons in the newborn puppy (15), but higher than that of juxtamedullary nephrons at birth in the lamb (1). The sequence of changes in regional glomerular perfusion rate from birth to maturity has not been established in the guinea pig. Because superficial single nephron glomerular filtration rate increases more rapidly than deep nephron filtration from 10-20 days of age $(5,17)$, it is notable that OC glomerular perfusion remained proportional to that of MC and IC. Furthermore, because the net ultrafiltration pressure did not increase in euvolemic sham-operated guinea pigs from 10 20 days of age (7), the observed maturational rise in superficial single nephron glomerular filtration rate may be due in part to an increase in ultrafiltration coefficient.

Compensatory renal growth. Although uninephrectomy at birth resulted in a significant elevation in arterial blood pressure, cardiac output was not maintained at a higher level. In contrast, LopezNovoa et al. (14) reported a $20 \%$ increase in cardiac output (but no change in arterial pressure) $48 \mathrm{~h}$ after uninephrectomy in the adult rat (14). These systemic hemodynamic effects of reduced renal mass may be mediated by renin release by the remaining kidney or altered adrenergic tone. The adaptive rise in renal blood flow demonstrated 20 days after uninephrectomy in the guinea pig could therefore be explained only by a primary fall in renal
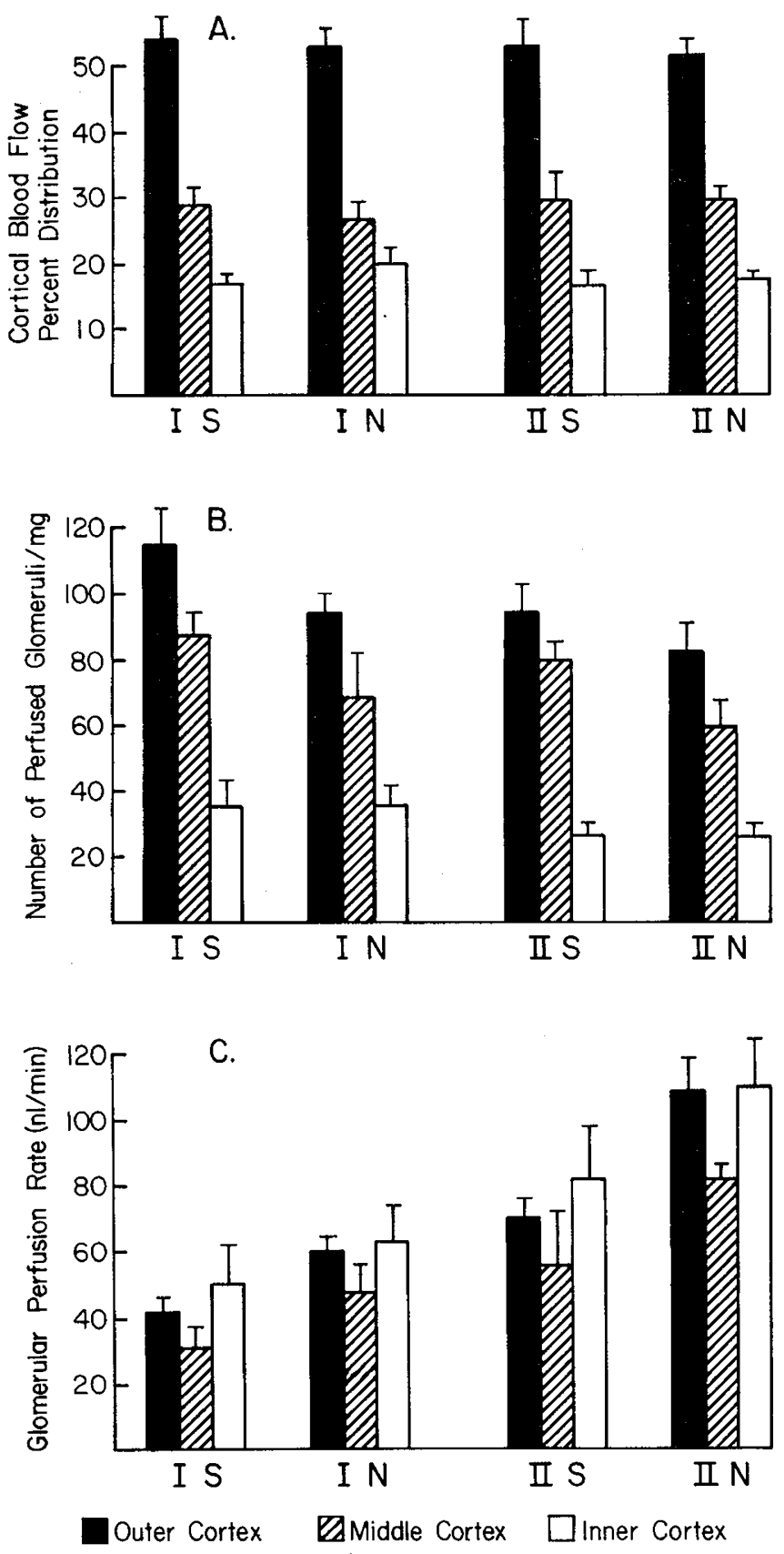

Fig. 2. $(A)$ Distribution of cortical blood flow in left kidney. $(B)$ Density of glomeruli identified by India ink perfusion for tissue from each cortical level. $(C)$ Glomerular perfusion rate. Each bar represents mean \pm SE for five animals.

vascular resistance, which decreased out of proportion to resistance in other organs. As shown in a previous study of the developing guinea pig, uninephrectomy at birth results in earlier "recruitment" of glomeruli, which normally remain underperfused until after $3 \mathrm{wk}$ of age (6). Vasodilation of underperfused glomeruli may thus contribute to the decreased relative renal vascular resistance of Group IIN.

In the adult rat, filtration fraction falls after uninephrectomy (14) or ablation of $75 \%$ of renal tissue (12), but no change was found in the dog with reduced renal mass (3). The lack of change in filtration fraction in the uninephrectomized guinea pig presumably reflects enhancement of forces for glomerular filtration which balance the fall in renal vascular resistance. Absence of a disproportionate increase in OC glomerular perfusion rate in Group IN compared with IS also contrasts with the greater compensatory increase in superficial than deep nephron single nephron glomerular filtration rate resulting from uninephrectomy at birth (5). But 
this adaptive rise in superficial nephron function may depend more on hemodynamic factors, as effective filtration pressure is significantly higher in uninephrectomized guinea pigs than in sham-operated litter-mates (7). It is likely that the significant rise in OC glomerular perfusion resulting from normal or compensatory renal growth also contributes to the rise in glomerular filtration rate of the developing guinea pig, although achievement of filtration equilibrium has not been demonstrated in this species.

In the adult rat subjected to uninephrectomy or ablation of $75 \%$ of renal mass, zonal perfusion shifted from outer to deeper nephrons when compared to sham-operated controls (12). Similarly, ablation of $75 \%$ of renal mass in the 2-month-old dog resulted in augmented glomerular perfusion of the deep cortex without change in OC glomerular perfusion (3). When renal mass was reduced at birth, however, the increase in glomerular perfusion occurred in all but the deepest cortical level (3). Because glomerular perfusion increased significantly in the OC of the uninephrectomized newborn guinea pig, the pattern of glomerular perfusion is more similar to that of the puppy than of the adult dog or rat. It appears, therefore, that age-related differences in adaptation to reduced renal mass are more important than species differences.

Normal versus compensatory renal growth. Hemodynamic changes resulting from uninephrectomy in the newborn guinea pig appear to be similar to those associated with normal renal development. Arterial blood pressure and renal blood flow increase with normal or compensatory renal growth. Although the rise in renal blood flow resulting from uninephrectomy is due to a primary fall in renal vascular resistance, that due to normal growth may also depend in part on increasing cardiac output. The pattern of intrarenal blood flow distribution was not altered and glomerular perfusion increased in all cortical levels with either normal or compensatory renal growth. Hemodynamic responses of the newborn to renal growth are therefore independent of the stimulus to increased renal function. The magnitude of renal adaptation depends on summation of separate stimuli: somatic growth and residual renal mass.

\section{REFERENCES AND NOTES}

1. Aperia, A., Broberger, O., and Herin, P.: Maturational changes in glomerula perfusion rate and glomerular filtration rate in lambs. Pediatr. Res., 8: 758
(1974)

2. Aperia, A. and Herin, P.: Development of glomerular perfusion rate and nephron filtration rate in rats 17-60 days old. Am. J. Physiol., 228: 1319 (1975).

3. Aschinberg, L. C., Koskimies, O., Bernstein, J., Nash, M., Edelmann, C. M., Jr and Spitzer A.: The influence of age on the response to renal parenchymal loss. Yale J. Biol. Med., 51: 341 (1978).

4. Bankir, L., Tan, M-M. T. T., and Grünfeld, J-P.: Measurement of glomerular blood flow in rabbits and rats: Erroneous findings with $15-\mu \mathrm{m}$ microspheres. Kidney Intern, 15: 126 (1979).

5. Chevalier, R. L.: Functional adaptation to reduced renal mass in early development. Am. J. Physiol., 242: F190 (1982)

6. Chevalier, R. L.: Glomerular number and perfusion during normal and compensatory renal growth in the guinea pig. Pediatr. Res., 16: 436 (1982)

7. Chevalier, R. L.: Reduced renal mass in early postnatal development: glomerular dynamics in the guinea pig. Clin. Res., 29: 903A (1981).

8. Fay, F. S. and Cooke, P. H.: Guinea pig ductus arteriosus. II. Irreversible closure after birth. Am. J. Physiol., 222: 841 (1972).

9. Gruskin, A. B., Edelmann, C. M., Jr., and Yuan, S.: Maturational changes in renal blood flow in piglets. Pediatr. Res., 4: 7 (1970).

10. Horster, M. and Lewy J. E.: Filtration fraction and extraction of PAH during neonatal period in the rat. Am. J. Physiol., 219: 1061 (1970).

11. Källskog, O., Lindbom, L. O., Ulfendahl, H. R., and Wolgast, M.: Regional and single glomerular blood flow in the rat kidney prepared for micropuncture. A methodological study. Acta Physiol. Scand., 94: 145 (1975).

12. Kaufman, J. M., Siegel, N. J., and Hayslett J. P.: Functional and hemodynamic adaptation to progressive renal ablation. Circ. Res., 36: 286 (1975)

13. Kleinman, L. I. and Reuter, J. H.: Maturation of glomerular blood flow distribution in the new-born dog. J. Physiol., 228: 91 (1973).

14. Lopez-Novoa, J. M., Ramos, B., Martin-Oar, J. E., and Hernando, L.: Functiona compensatory changes after unilateral nephrectomy in rats. Renal Physiol., 5 : 76 (1982).

15. Olbing, H., Blaufox, M. D., Aschinberg, L. C., Silkalns, G. I., Bernstein, J., Spitzer, A., and Edelmann, C. M., Jr.: Postnatal changes in renal glomerular blood flow distribution in puppies. J. Clin. Invest., 52: 2885 (1973).

16. Robillard, J. E., Weismann, D. N., and Herin P.: Ontogeny of single glomerular perfusion rate in fetal and newborn lambs. Pediatr. Res., 15: 1248 (1981)

17. Spitzer, A. and Brandis, M.: Functional and morphologic maturation of the superficial nephrons. J. Clin. Invest., 53: 279 (1974).

18. The author gratefully acknowledges Dr. Donald Kaiser for performing statistica analyses; James G. Bowman, Jr., for technical assistance; and Lynne Damien and Debi Mack for secretarial assistance.

19. Requests for reprints should be addressed to: Robert Chevalier, M. D., Department of Pediatrics, Box 386, University of Virginia Medical School, Charlottesville, Virginia 22908 , U.S.A.

20. This study was supported by National Institutes of Health Grants R01-AM 25727 and 5-207-RR05431-17.

21. Received for publication July 1, 1982

22. Accepted for publication December 21, 1982. 